\title{
Prevalence of Associated Factors of Depressive Symptoms among School Going Children
}

\author{
Sonal Balwantrao Dhobe ${ }^{1}$, Samrudhhi Subhashrao Gujar² \\ 1, 2 Department of Medical Surgical Nursing, Smt. Radhikabai Meghe Memorial College of Nursing, DMIMS \\ (Deemed to Be University), Sawangi (Meghe), Wardha, Maharashtra, India.
}

\section{ABSTRACT}

\section{BACKGROUND}

A broad spectrum of emotional lows, from simple sadness to a pathological suicidal condition is defined as a depression. This is a common mental illness that has been noticed in daily life. Usually, a person who is depressed or feeling unhappy may return to normal emotional health within a specified time. There are times where this condition stretches for such a time that it is greatly overshadowed by the value of the precipitating factor. The patient in a prolonged depression state withdraws from his / her private, social, and professional activities. In some scenarios the diagnosis of depression should be identified. According to epidemiological studies, 15 percent to 20 percent of the children and adolescents experience at least one depressive episode in life and this is a common recurrent and impairing condition that predicts future suicide attempts, academic failure, interpersonal problems, unemployment, substance abuse, and delinquency before adulthood. The objective of the study was to assess the prevalence of associated factors of depressive symptoms among school going children and to evaluate the association of the prevalence score with selected demographic variables.

\section{METHODS}

This was a cross sectional study with quantitative research approach. The study was conducted in a selected school of Wardha district. Nonprobability convenience sampling technique was used to collect data from school going children. A structured questionnaire including socio demographic details \& patient health questionnaire (PHQ-9) scale was used to identify the prevalence of depressive symptoms among school going children. After collecting data, the sample characteristics were described by frequency and percentage. A chi-square test was used to find out the relationship between the association between prevalence of associated factors of depressive symptoms and selected demographic variables.

\section{RESULTS}

In this study $8.89 \%$ of school going children had no depression; minimal depression was seen in $68.89 \%$; mild depression in $17.88 \%$, moderate depression in $4.44 \%$, and moderately severe depression in $0 \%$ of school going children were seen.

\section{CONCLUSIONS}

There was a significant association between the prevalence of associated factors of depressive symptoms among school going children with gender only.

\section{KEY WORDS}

Prevalence, Associated Factors, Depressive Symptoms, School Going Children
Corresponding Author: Sonal Balwantrao Dhobe, Department of Medical Surgical Nursing, Smt. Radhikabai Meghe Memorial College of Nursing, DMIMS (Deemed to Be University), Sawangi (Meghe), Wardha, Maharashtra, India.

E-mail: dhobesonal67@gmail.com

DOI: $10.14260 / j e m d s / 2021 / 226$

How to Cite This Article:

Dhobe SB, Gujar SS. Prevalence of associated factors of depressive symptoms among school going children. J Evolution Med Dent Sci 2021;10(15):1060-1063, DOI: 10.14260/jemds/2021/226

Submission 26-10-2020,

Peer Review 09-02-2021,

Acceptance 15-02-2021,

Published 12-04-2021.

Copyright (C) 2021 Sonal Balwantrao Dhobe et al. This is an open access article distributed under Creative Commons Attribution License [Attribution 4.0 International (CC BY 4.0)] 


\section{BACKGROUND}

A broad spectrum of emotional lows, from simple sadness to a pathological suicidal condition is defined as a depression. ${ }^{1}$ This is a common mental illness that has been noticed in daily life. Usually, a person who is depressed or feeling unhappy may return to normal emotional health within a specified time. ${ }^{2}$ There are times where this condition stretches for such a time that it is greatly overshadowed by the value of the precipitating factor. The patient in a prolonged depression state and withdraws from his / her private, social, and professional activities. In some scenarios the diagnosis of depression should be identified. ${ }^{3}$

In the adolescent age group, the effects of depression are phenomenal. ${ }^{4}$ Moderate to extreme depression can influence adolescent's academic success. Overall, students are at risk of habits like drug abuse to get over depression. A major depressive disorder is also found to be a leading cause of adolescent suicidal behaviour and suicides. ${ }^{5}$ There is also a recurrent course of waxing and fading of adolescent depressive disorder and there is a fourfold risk of persisting depression in adulthood. ${ }^{6}$ Research also shows that the onset of depression happens earlier in today's life than in the previous decades. ${ }^{7}$ Rapid urbanization and lifestyle changes may be the reasons for this. Evidence suggests that early intervention for depression in children may enhance longterm performance. ${ }^{8}$

Depression is one of the most prominent global mental health problems. It is one of the under-recognised health concerns in teenagers because of the failure to reveal their emotions and refusal to seek professional assistance. In the last century, the medical profession did not understand the existence of depressive problems in children. However, many studies show that children not only suffer a broad spectrum of mental illnesses but also experience severe morbidity and mortality associated with them. Recent research also confirmed the prevalence of depression (10 percent - 60 percent) in teenagers. ${ }^{9}$

The transition stage from childhood to adulthood is a phase characterised by mental distress that causes adolescents vulnerable to depression. During this time, behavioural changes associated with hormonal changes make depression difficult to diagnose. It is reported that over 70 percent of children with depression are not adequately managed. ${ }^{10}$ Symptoms of depression were described in the Fifth Edition of the Diagnostic and Statistical Manual of Mental Disorders, including depressed moods, elevated mood or derangement, general decline or enjoyment, insomnia, fatigue or lack of energy, decreased ability to focus, severe weight loss, thoughts of uselessness or extreme regret, and recurrent thoughts of suicide. The guidelines for depressive disorders are identified by people with five or more of these signs. ${ }^{11}$

Depression is the fourth most important illness according to the Murray 2006 disease burden assessment. A widespread issue with prevalence rate reported to be high as 12 percent in young people. 86 million people of South Asians are affected by depression, in India mostly the 13 - 15 years age group children are affected by depression. Depression is related to low academic performance, social instability, drug abuse, suicide attempts, and suicide. There are some programmes to prevent the occurrence of depression and reviews to assess the evidence of effectiveness of the prevention programs in selected areas. ${ }^{12}$

\section{Objectives}

1. To assess the prevalence of associated factors of depressive symptoms among school going children.

2. To associate the prevalence score with selected demographic variables.

\section{METHODS}

This cross-sectional study was performed between September 2019 and September 2020 in the Wardha district. This descriptive research was carried out among 45 school-going children in the chosen Wardha district school.

The research was accepted by the IEC committee on institutional ethics. (Ref. no: DMIMS (DU) / IEC / Dec-2019 / 8648), Sawangi (Meghe), Wardha, Datta Meghe Institute of Medical Sciences (Deemed to Be University). Non-probability convenience sampling technique was used to obtain data from the samples. The research included all school children who were $6-13$ years old, eligible to engage in the study and available for data collection at that time and excluded those taking psychiatric therapy or attending a similar type of study.

Permission was received from the authorities at the selected school concerned. The researcher approached the school going children in the age group of $6-13$ years and explained the purpose and benefits of the study. The investigator took the consent of the local guardian for individual school going children, visited each child separately, and provided guidance on the study. Administered a standardised checklist (PHQ-9) scale. The investigator instructed them not to communicate with each other, in case of any questions, they could clarify their doubts by questioning and investigating.

The questionnaire consisted two parts, one part consisted of demographic data of school going children such as age, gender, educational level, type of family, monthly family income, religion and the other part consisted PHQ-9 scale, which had 9 questions related to associated factors of depressive symptoms knowledge among school going children.

\section{Statistical Analysis}

The statistical analysis was done by using SPSS 23 software. For categorical variables, frequencies and percentages were presented. Statistical analysis of the prevalence of associated factors of depressive symptoms among school going children was carried out to find the significant difference between those values. Analysis of the data was done by using descriptive and inferential statistics.

\section{RESULTS}

Table 1 shows that $17.80 \%$ of the school going were 6 - 7 years old, $28.90 \%$ were 8 - 9 years old and $26.70 \%$ each were in the age group of $10-11$ years and $12-13$ years. Majority of the of 
school going children were females, $55.60 \%$ and $44.40 \%$ were males. $28.90 \%$ were educated up to 3rd standard, $31.10 \%$ up to 4 th standard, $15.60 \%$ were educated up to 5 th standard and $24.40 \%$ of them were educated up to 6 th standard. 46.70 $\%$ belonged to nuclear family and $53.30 \%$ of them were belonging to joint families. $31.10 \%$ of the school going children had a monthly family income of 5000 - 1000 Rs, 26.70 $\%$ had between 10001 - 11000 Rs, $22.20 \%$ had between $11001-12000$ Rs and $20 \%$ of them were having monthly family income of $12001-13000$ Rs. $42.20 \%$ were Hindus, $48.90 \%$ were Muslims, $6.70 \%$ were Buddhist and $2.20 \%$ belonged to other religions.

\begin{tabular}{|c|c|c|c|}
\hline & $\begin{array}{c}\text { Demographic } \\
\text { Variables }\end{array}$ & $\begin{array}{l}\text { No. of School } \\
\text { Going Children }\end{array}$ & $\begin{array}{c}\text { Percentage } \\
(\%)\end{array}$ \\
\hline \multirow{4}{*}{ Age (yrs.) } & 6 - 7 yrs. & 8 & 17.8 \\
\hline & $8-9$ yrs. & 13 & 28.9 \\
\hline & $10-11$ yrs. & 12 & 26.7 \\
\hline & $12-13$ yrs. & 12 & 26.7 \\
\hline \multirow{2}{*}{ Gender } & Male & 20 & 44.4 \\
\hline & Female & 25 & 55.6 \\
\hline \multirow{4}{*}{ Educational level } & $3^{\text {rd }}$ standard & 13 & 28.9 \\
\hline & $4^{\text {th }}$ standard & 14 & 31.1 \\
\hline & $5^{\text {th }}$ standard & 7 & 15.6 \\
\hline & $6^{\text {th }}$ standard & 11 & 24.4 \\
\hline \multirow{2}{*}{ Type of family } & Nuclear & 21 & 46.7 \\
\hline & Joint & 24 & 53.3 \\
\hline \multirow{4}{*}{$\begin{array}{l}\text { Monthly family } \\
\text { income (Rs) }\end{array}$} & $5000-10000 \mathrm{Rs}$ & 14 & 31.1 \\
\hline & $10001-11000$ Rs & 12 & 26.7 \\
\hline & $11001-12000 \mathrm{Rs}$ & 10 & 22.2 \\
\hline & $12001-13000 \mathrm{Rs}$ & 9 & 20.0 \\
\hline \multirow{4}{*}{ Religion } & Hindu & 19 & 42.2 \\
\hline & Muslim & 22 & 48.9 \\
\hline & Buddhism & 3 & 6.7 \\
\hline & Others & 1 & 2.2 \\
\hline
\end{tabular}

\begin{tabular}{|c|c|c|c|}
\hline \multirow[b]{2}{*}{ Level of PHQ-9 Score } & \multirow[b]{2}{*}{ Score Range } & \multicolumn{2}{|c|}{ Level of PHQ-9 Score } \\
\hline & & $\begin{array}{l}\text { No of School } \\
\text { Going Children }\end{array}$ & Percentage \\
\hline No depression & 0 & 4 & 8.89 \\
\hline Minimal depression & $1-4$ & 31 & 68.89 \\
\hline Mild depression & $5-9$ & 8 & 17.88 \\
\hline Moderate depression & $10-14$ & 2 & 4.44 \\
\hline Moderately severe depression & $15-19$ & 0 & 0 \\
\hline Severe depression & $20-27$ & 0 & 0 \\
\hline \multicolumn{2}{|l|}{ Minimum score } & \multicolumn{2}{|l|}{0} \\
\hline \multicolumn{2}{|l|}{ Maximum score } & \multicolumn{2}{|c|}{14} \\
\hline \multicolumn{2}{|l|}{ Mean PHQ-9 score } & \multicolumn{2}{|c|}{$3.26 \pm 2.79$} \\
\hline \multicolumn{2}{|c|}{ Mean \% PHQ-9 score } & \multicolumn{2}{|c|}{$12.09 \pm 10.39$} \\
\hline \multicolumn{4}{|c|}{ Table 2. Prevalence of Associated Factors (PHQ-9) N = 45} \\
\hline
\end{tabular}

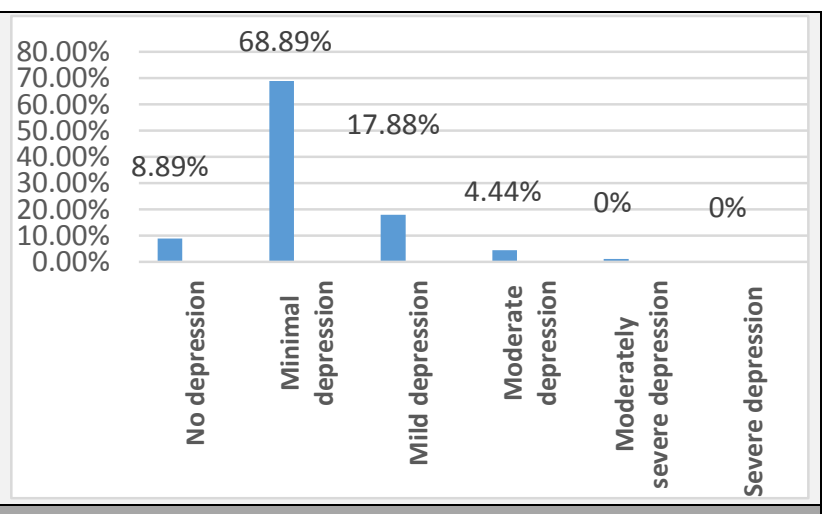

Graph 1. Prevalence of Associated Factors (PHQ-9) N = 45
Table 2 and Graph 1 shows that $8.89 \%$ of the school going children had no depression, $68.89 \%$ had minimal depression, $17.88 \%$ had mild depression, and $4.44 \%$ of the school going children had moderate depression.

\begin{tabular}{|c|c|c|c|c|c|}
\hline & $\begin{array}{c}\text { Demographic } \\
\text { Variable }\end{array}$ & $\begin{array}{l}\text { No. of School } \\
\text { Going } \\
\text { Children }\end{array}$ & $\begin{array}{c}\text { Mean PHQ- } \\
9 \text { score }\end{array}$ & f-Value & $\begin{array}{c}\text { P- } \\
\text { Value }\end{array}$ \\
\hline \multirow{4}{*}{ Age (yrs.) } & $6-7$ yrs. & 8 & $3.37 \pm 2.50$ & \multirow{4}{*}{0.42} & \multirow{4}{*}{$\begin{array}{c}0.73 \\
\text { NS, P > } \\
0.05\end{array}$} \\
\hline & 8 - 9 yrs. & 13 & $2.53 \pm 1.94$ & & \\
\hline & 10 - 11 yrs. & 12 & $3.50 \pm 2.93$ & & \\
\hline & $12-13$ yrs. & 12 & $3.75 \pm 3.69$ & & \\
\hline \multirow{2}{*}{ Gender } & Male & 20 & $2.30 \pm 2.10$ & \multirow{2}{*}{2.15} & 0.037 \\
\hline & Female & 25 & $4.04 \pm 3.07$ & & $\begin{array}{c}\mathrm{S}, \mathrm{P}< \\
0.05\end{array}$ \\
\hline \multirow{4}{*}{$\begin{array}{l}\text { Educational } \\
\text { level }\end{array}$} & $3^{\text {rd }}$ standard & 13 & $4 \pm 2.41$ & \multirow{4}{*}{0.59} & \multirow{4}{*}{$\begin{array}{c}0.62 \\
\mathrm{NS}, \mathrm{P}> \\
0.05\end{array}$} \\
\hline & $4^{\text {th }}$ standard & 14 & $3.07 \pm 2.70$ & & \\
\hline & $5^{\text {th }}$ standard & 7 & $2.28 \pm 1.49$ & & \\
\hline & $6^{\text {th }}$ standard & 11 & $3.27 \pm 3.90$ & & \\
\hline \multirow{2}{*}{$\begin{array}{l}\text { Type of } \\
\text { family }\end{array}$} & Nuclear & 21 & $3.23 \pm 1.60$ & \multirow[b]{2}{*}{0.06} & \multirow{2}{*}{$\begin{array}{c}0.95 \\
\mathrm{NS}, \mathrm{P}> \\
0.05\end{array}$} \\
\hline & Joint & 24 & $3.29 \pm 3.56$ & & \\
\hline \multirow{4}{*}{$\begin{array}{c}\text { Monthly } \\
\text { family } \\
\text { income (Rs) }\end{array}$} & $5000-10000$ Rs & 14 & $3.21 \pm 2.39$ & \multirow{4}{*}{0.11} & \multirow{4}{*}{$\begin{array}{c}0.95 \\
\mathrm{NS}, \mathrm{P}> \\
0.05\end{array}$} \\
\hline & $10001-11000 \mathrm{Rs}$ & 12 & $3.66 \pm 4.33$ & & \\
\hline & $11001-12000 \mathrm{Rs}$ & 10 & $3 \pm 1.56$ & & \\
\hline & $12001-13000 \mathrm{Rs}$ & 9 & $3.11 \pm 2.20$ & & \\
\hline \multirow{4}{*}{ Religion } & Hindu & 19 & $3.26 \pm 2.60$ & \multirow{4}{*}{0.06} & \multirow{4}{*}{$\begin{array}{c}0.97 \\
\mathrm{NS}, \mathrm{P}> \\
0.05\end{array}$} \\
\hline & Muslim & 22 & $3.31 \pm 3.18$ & & \\
\hline & Buddhism & 3 & $2.66 \pm 2.08$ & & \\
\hline & Others & 1 & $4 \pm 0$ & & \\
\hline & $\begin{array}{r}\text { Table 3. Associa } \\
\text { Demog }\end{array}$ & $\begin{array}{l}n \text { of } P H Q-9 S \\
\text { hic Variabl }\end{array}$ & $\begin{array}{l}\text { ore in Relat } \\
\text { s. } N=45\end{array}$ & & \\
\hline
\end{tabular}

Table 3 shows that the religion of school going children is statistically not associated with their PHQ-9 score. There is a significant association with gender of school going children. Other demographic variables are not significantly associated with the prevalence of nutritional anaemia. Because the tabulated values were much higher, they were calculated at 5 $\%$ level of significance. Also, the calculated $\mathrm{P}$ value was much higher than the acceptable level of significance i.e., ' $\mathrm{P}$ ' $=0.05$. Hence, it is interpreted that socio demographic variable of adolescent girls is statistically not associated with prevalence of nutritional anaemia.

\section{DISCUSSION}

A patient health questionnaire (PHQ-9) scale was used to find the prevalence of associated factors of depressive symptoms. This scale described no depression as 0 , minimal depression as $1-4$, mild depression as $5-9$, moderate depression as 10 14 , and moderately severe depression as 15 - 19. In this study we found $8.89 \%$ of school going children had no depression, minimal depression in $68.89 \%$, mild depression in $17.88 \%$, and moderate depression in $4.44 \%$, moderately severe depression in $0 \%$.

Similar study was conducted by Man Mohan Singh et al. which was a cross-sectional study conducted in the year 2017 by selecting 542 random school going adolescents in the age group of 13 - 18 years. The sample was selected for this study from eight schools by using a multistage sampling technique. Depression was assessed by using PHQ-9 scale with semi structured interview method, multistage analysis was done to identify significant associated factors. There was a depressive 
disorder in 40 percent of teenagers, 7.6 percent major depressive disorder, and 32.5 percent other depressive disorder. In terms of intensity, $29.7 \%$ had mild depression, 15.55 had moderate depression, $3.7 \%$ had fairly extreme depression, and $1.1 \%$ had severe depression. ${ }^{13}$

Another similar study was conducted by Mr. Mukesh Shukla et al. which was a cross sectional study conducted among 2187 school-going adolescent girls in the age group of 10 - 19 years at Barabanki district from September 2016 to September 2017, the sample collection was done by using multistage sampling. To measure depression, the Eleven-item Kutcher Adolescent Depression Scale was used. There were depressive symptoms in about a third of school-going teenage girls. The prevalence of depression was 39.7 percent. ${ }^{14}$

\section{Prevalence of Associated Factors of Depressive Symptoms Associated with Gender}

Prevalence of associated factors of depressive symptoms was associated with gender in the present study, $\mathrm{P}=0.037$ was significant. Hence, it is interpreted that there was a significant association with gender which explains that female have higher prevalence of associated factors of depressive symptoms than boys.

A similar cross-sectional study was done by Afifa Anjum et al. The purpose of the research was to investigate the prevalence and factors associated with depressive symptoms among adolescents in urban and semi-urban schools in Bangladesh. In this study, female adolescents had signs of depression more than twice than their male counterparts, which is consistent with the research results carried out in other Asian countries. In this analysis, a substantial association with depressive symptoms in the current study explains that girls had a higher prevalence of 85 (42.9) percent. 15

A study by Kunal Kishor Jha et al. was conducted in Bihar in 2017 which indicates a higher prevalence in girls. This research was for prevalence of depression among schoolgoing adolescents in Bihar, India, in urban region.

\section{CONCLUSIONS}

The study shows that $8.89 \%$ of the school going children had no depression; $68.89 \%$ had minimal depression; $17.88 \%$ had mild depression; and $4.44 \%$ of the school going children had moderate depression. There was a significant association between the prevalence of associated factors of depressive symptoms among school going children with gender only.

\footnotetext{
Limitations

Our study focused only on the prevalence of associated factors of depressive symptoms among school going children, limited to the Wardha district and among children of $6-13$ years age group only.

Data sharing statement provided by the authors is available with the full text of this article at jemds.com.

Financial or other competing interests: None.

Disclosure forms provided by the authors are available with the full text of this article at jemds.com.
}

\section{REFERENCES}

[1] American Academy of Pediatrics. Feeding your baby: breast and bottle. Chap - 4. In: Shelov SP, edr. Caring for your baby and young child: birth to age $5.5^{\text {th }}$ edn. New York: Bantam Books 2009: p. 91-3.

[2] Neifert MR. The optimization of breast-feeding in the perinatal period. Clinics in Perinatology 1998;25(2):30326.

[3] Marlett LA. The breastfeeding practices of women with a history of breast cancer. UNLV Retrospective Theses \& Dissertations 1998: p. 935.

[4] Masoud AAM. The effect of cabbage leaves on relief breast engorgement among postpartum women (Doctoral dissertation, Benha University). Obstetric and Gynecological Nursing 2018.

[5] James W, Berger T, Elston D. Andrew's Diseases of the skin e-book: clinical dermatology. $11^{\text {th }}$ edn. Saunders/Elsevier Health Sciences 2011.

[6] Frida SKR. Effectiveness of closed system manual breast pump versus hand expression on breast engorgement among postnatal mothers admitted in postnatal ward at Government Rajaji Hospital, Madurai. Masters Thesis, College of Nursing, Madhurai Medical College, Madhurai. The Tamil Nadu Dr. M. G. R. Medical University 2016.

[7] Reena M, Rajeswari S, Sumathi MR. Effectiveness of lactational counseling on breast engorgement and newborn feeding behavior among primigravidae at Sri Ramachandra Hospital. Journal of Medical Science and Clinical Research 2015;3(9):7396-403.

[8] Riordan J, Wambach K. Breastfeeding and human lactation. $4^{\text {th }}$ edn. Sudbury, Mass: Jones \& Bartlett Learning 2010.

[9] Padmasree SR, Varghese L, Krishnan AS. Effectiveness of prenatal teaching on prevention of breast engorgement. Int J Reprod Contracept Obstet Gynecol 2017;6(9):39271.

[10] American Psychiatric Association. Diagnostic and statistical manual of mental disorders. $5^{\text {th }}$ edn. Arlington, VA: American Psychiatric Publishing 2013.

[11] Possel P, Seemann S, Hautzinger M. Impact of comorbidity in prevention of adolescent depressive symptoms. Journal of Counseling Psychology 2008;55(1):106-17.

[12] Singh MM, Gupta M, Grover S. Prevalence \& factors associated with depression among schoolgoing adolescents in Chandigarh, North India. Indian J Med Res 2017;146(2):205-15.

[13] Shukla M, Ahmad S, Singh JV, et al. Factors associated with depression among school-going adolescent girls in a district of Northern India: a cross-sectional study. Indian J Psychol Med 2019;41(1):46-53.

[14] Jha KK, Singh SK, Nirala SK, et al. Prevalence of depression among school-going adolescents in an urban area of Bihar, India. Indian J Psychol Med 2017;39(3):287-92.

[15] Khan A, Ahmed R, Burton NW. Prevalence and correlates of depressive symptoms in secondary school children in Dhaka city, Bangladesh. Ethn Health 2020;25(1):34-46. 